Research Paper

\title{
The efficiency analysis of thrombolytic rt-PA combined with intravascular interventional therapy in patients with acute basilar artery occlusion
}

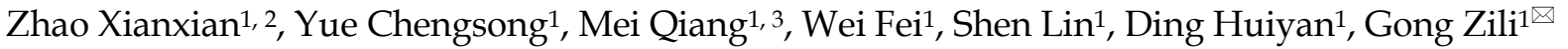 \\ 1. Department of Neurology, xinqiao hospital affiliated Third Military Medical University, Chongqing 400037, China. \\ 2. Administration Office for Undergraduates, Third Military Medical University, Chongqing 400038, China. \\ 3. Department of Neurology, The 169th hospital of P.L.A. Hengyang, 421002, Hunan, China. \\ $\triangle$ Corresponding author: Gong Zili, email: gzl_945@163.com. \\ (c) Ivyspring International Publisher. This is an open access article distributed under the terms of the Creative Commons Attribution (CC BY-NC) license \\ (https://creativecommons.org/licenses/by-nc/4.0/). See http://ivyspring.com/terms for full terms and conditions.
}

Received: 2016.01.27; Accepted: 2016.02.09; Published: 2017.01.01

\begin{abstract}
In order to further optimize the treatment strategy for the patients with acute basilar artery occlusion, we were dedicated to study the therapeutic effects and influential factors in the process of treated basilar artery occlusion with thrombolytic combined vascular interventional therapy. 75 patients with acute basilar artery occlusion treated with arterial thrombolytic therapy were analyzed retrospectively. In accordance with the discharge records of patients, their short-term curative effect with 24-hour treatment and 14-days treatment were evaluated. Our data showed that the survival condition of the patients with acute acute basilar artery occlusion were visibly improved by combination thrombolytic and interventional therapy. Moreover, their Bl scores were remarkably improved, while NIHSS and mRS scores were evidently reduced. These data proved that our treatment strategy was able to improve the survival condition of patients with acute basilar artery occlusion. Furthermore, our data showed that coagulation related factors remarkably improved in the patients, when they treated by combination thrombolytic therapy with interventional therapy. In addition, our results suggested that the patients' bilateral Babinski(+), revascularization and coma symptom were closely related to their prognosis after treated the patients with combination thrombolytic and vascular interventional therapy, and the difference was statistically significant $(p<0.05, p<0.05, p<0.05)$. Besides, our data also displayed that the with stent assisted angioplasty was significantly superior to the patients with balloon angioplasty, and the difference was statistically significant $(p<0.05)$. Anyhow, combination thrombolytic with interventional therapy can effectively promote the prognosis of the patients with acute basilar artery occlusion. The coma symptom, bilateral Babinski(+), and revascularization in the patients with acute basilar artery occlusion have an appreciable impact on the patients' prognosis.
\end{abstract}

Key words: acute basilar artery occlusion; thrombolytic therapy; interventional therapy; rt-PA.

\section{Introduction}

It has been reported that posterior circulation ischemia caused by basilar artery insufficiency taken account for about $20 \%$ in the patients with ischemic stroke[1]. The mortality and disability rate of basilar artery occlusion are considerable in clinic, such as its mortality rate is up to $85 \%-95 \%$ [2]. Moreover, among the survival cases after surgical treatment, a large proportion of cases are in the vegetative state[3]. In which basilar artery occlusion (BAO) is the worst ischemic stroke subtype in the prognosis [2], and the key to successfully fight against basilar artery occlusion in the clinic is to restore blood flow as soon as possible[4]. Although anticoagulation and antiplatelet method have been widely used in the clinic by many doctors, $80 \%-90 \%$ patients still can not avoid death[5]. Recent reports have showed that 
thrombolytic therapy can effectively decrease the mortality rate and greatly improve patients' quality of life [6].

The basilar artery is the main blood supply vessels of brain stem, if its main trunk occlusion, it will be easy to injure the brain stem area, nerve nucleus and other brain structures, which will raise the mortality and disability rate in the acute stage [4]. Patients with acute basilar artery occlusion have a severe damage in their neurologic function, but they have abundant collateral vessels and excellent ability to tolerate ischemia, so that it is proper to appropriately extend therapeutic stage during the thrombolytic therapy, which is useful to the re-vascularize and restore the blood supply to the obstacle area of blood supply [7].

So far, it has been proved that recombinant tissue plasminogen activator (rt-PA) is the only treatment method that can decrease the disability rate of patients with ischemic stroke [8]. The prognosis of basilar artery occlusion mainly depends on the infarct site, the method and time of treatment, and the degree of vascular reconstruction and so on [9], and its treatment methods mainly consists of arterial thrombolysis, intravenous thrombolysis, combined arterial with intravenous thrombolysis, basilar artery stenting and mechanical thrombectomy[10,11], among which arterial thrombolysis and intravenous thrombolysis are commonly used in the clinic. For the patients with confirmed diagnosis, they will benefit more by extending rt-PA stage in the process of intravenous thrombolysis. Grond et al. have found that it will have a good curative effect for the patients with basilar artery occlusion via treated with thrombolytic therapy in 3 hours after the onset [12].

On the basis of thrombolytic therapy, we further introduced interventional vascular embolization, namely superselective intra-arterial embolization, to treat the patients with basilar artery occlusion, which is one of the interventional endovascular treatments [13]. Superselective intra-arterial embolization is a novel diagnostic and therapeutic technology, which was developed from the catheter technology in 1950s. Along with the development of X-ray imaging technology [14], especially the construction of computer digital subtraction angiography in 1970s, doctors can put a special catheter into a small artery in almost any diseased area under a fluorescent screen [15]. Moreover, it has more clear angiography, relatively smaller trauma, more effective treatment, and it can be used repeatedly without serious and soft tissue deformity, accordingly prompted the treatments strategy develop broad prospects[13].

In the current study, firstly we analyzed the basic information of the patients with acute basilar artery occlusion admitted to our hospital, and appropriate treatment strategies were adopted in accordance with patients' willingness. Then, the efficacy and prognosis of different treatment strategies was statistically analyzed. Moreover, in order to provide reference and help for the follow-up clinical, the factors that may affect prognosis of the patients with acute basilar artery occlusion were furtherly analyzed.

\section{Methods and Materials}

\section{General information}

75 stroke patients with the symptoms of acute basilar artery occlusion: (1) it is confirmed that they have neurologic impairment caused by posterior circulation or basilar artery infarction by MRA; (2) they have typical symptoms, such as crossed paralysis, quadriplegia, a closed state or coma with brainstem function defect; (3) it is confirmed that they are in coma for acute posterior circulation dysfunction by CT or MRI. All of those patients are confirmed by cranial computed tomography or MRI after treated for 24 hours.

Inclusion criteria of patients treated through thrombolytic therapy: (1) aged 20-80; (2)Clinical symptoms are consistent with the diagnosis of ischemic stroke; (3) the time stage is within 24 hours from the onset to the treatment of stroke symptoms; (4) there is no low-density foci and the sign of intracranial hemorrhage from CT; (5) it is the first onset or has no previous significant sequelae stroke (mRS score < 1); (6) patients themselves or their families agree to sign the informed consent. Exclusion criteria: (1) the examination of CT or MRI reveals high-density lesions (bleeding), acute brain stem or low-density lesions in cerebellum; (2) coma or severe stroke symptoms (NIHSS $>25)$; (3) the rapid improvement of stroke symptoms before the thrombolytic therapy; (4) onset of the stroke in 6 weeks; (5) onset along with the seizures; (6) patients of active bleeding or a high degree of bleeding tendency; (7) difficultly control of high blood pressure and hyperglycemia (blood pressure $>180 / 105 \mathrm{~mm}$ $\mathrm{Hg}$, blood glucose $>22.2 \mathrm{mmoUL}$ ); (8) platelet count below 100×109/L; (9) patients with severe liver and kidney dysfunction or estimated life less than 1 years.

Inclusion criteria of patients treated with interventional therapy through the examination of cranial CT, 67 patients have no symptoms of brain hemorrhage and a large area of low-density lesions, as well as no taboo of arterial thrombolysis, includes: (1) clinical symptoms show a significant improvement; (2) bleeding tendency; (3) a history of surgery or trauma in 2 months; (4) Major organ dysfunction or 
failure; (5) systolic blood pressure before the treatment $>180 \mathrm{mmHg}$, or diastolic pressure $>110$ $\mathrm{mmHg}$.

\section{Main instruments and drugs}

Double C-arm rotational angiography machine (Siemens company), Guiding Catheter and wire (Cordis company), SP micro catheter system (Terumo company), Balloon (Braun and Medtronic companies), stent (Microport' Firebird and Cordis' Genesis), rt-PA (Boehringer-Ingelheim, Germany).

\section{Main process of diagnosis and treatment}

(1) After the systemic heparin, the aortic arch and total cerebral angiography were performed. (2) Guided by micro guiding wire, the micro catheter was placed in the distal end of the BAO, then it could be seen that basilar artery was occluded and the blood in the end flew unobstructedly, which can prove the acute occlusion of basilar artery. (3) The micro catheter was placed in the proximal end of the thrombus, and the drug was pumped into the thrombolytic agent by the micro pump. Actilyse (rt-PA) was used in the experiment. Patients would have $0.9 \mathrm{mg} / \mathrm{kg}$ according to their weight, and the maximum doze is $90 \mathrm{mg}$. $10 \%$ of the total doze would add to the syringe and mix them again, then slowly bolus for 1 minute; the rest $90 \%$ would use intravenous drip by the infusion pump for 1 hour or longer. After each drug pumped, check how well was the blood flowing in the basilar artery and its branches; if the blood is lucid, the operation ends; if the remaining of the basilar artery is severe stenosis $(\geq$ $70 \%$ ), balloon angioplasty or stent assisted angioplasty should be adopted. If the total drug is up to 1 million $U$, the operation should stop even if the basilar artery is occluded. (4) In stent therapy, the transverse diameter of the stent should be longer $0.5-1.0 \mathrm{~mm}$ than the normal diameter of the basilar artery; it should exceed $1-2 \mathrm{~mm}$ of both ends of the narrow blood vessel; the degree of dilatation of the vascular stenosis was $80 \%$ of the normal diameter of the basilar artery. (5) If patients have a severe headache, nausea, and vomiting during thrombolysis, they should immediately stop using the drugs and then perform the head CT quickly. (6) With natural neutralization of heparin after the thrombolysis therapy, the patients routinely transfer to the ICU and get supporting treatment; after their vital signs are stable, they can be transferred to the general ward. (7) Do the head CT 24 hours later since the operation is over; one week later do neck vascular and cerebral vascular ultrasound review. The contrast group should be provided with volume expansion, intracranial pressure decrease, anti-platelet, blood lipid, anti-oxidative modification, circulation improvement, and nutritional nerve agents.

\section{Observation indexes}

According to previous study [16], indexes follows (1) Compare two groups' survival rate and NIHSS score in 24 hours, 14 days, 90 days after the treatment, estimate BI of 14 days and 90 days and comprehensive viability of 90 days (improve the Rankin score, mRS score), and then record the adverse effect and complication. (2) Symptoms after admission to our hospital, including dizziness, coma, ocular tremor, and bilateral Babinski. (3) Vascular reperfusion: in view of the grading standard of TIMI, total vascular occlusion is named as grade 0; A small amount of blood flows through the occlusion site, and the distal end of the occlusion full of vascular bed is named as grade 1; the distal end of the occlusion is full of vascular bed, but filling and emptying delay is named as grade 2; the revascularization is named as grade 3 . For the convenience of analysis, grade 0 and 1 are defined as poor revascularization, and grade 2 and 3 are defined as good revascularization. (4) Treatment effects: discharged effect can be referred as the short-term effects, which are evaluated depend on the discharged medical records; the long-term effects are the follow-up results of 1 year after the discharge. The evaluation criteria refer to GOS prognostic scoring criteria. 5 points, namely patients can have normal life with good recovery; 4 points, namely patients can have independent life with mild disability; 3 points, patients cannot live independently for severe disability; 2 points, patients are in vegetative state; 1 point, death. For the convenience of analysis, the research defines 4 and 5 points of GOS as good prognosis, 1 to 3 points as poor prognosis. (5) Determine the blood vessel embolism by head Color Doppler Ultrasound after the treatment of $14 \mathrm{~d}$; (6) Changes of blood coagulation related indexes before and after treatment 4 hours.

\section{Postoperative follow-up}

The clinic follow-up can be made with telephone, hospitalization and outpatient department, which need to record preoperatively all complications of nervous system and non-nervous system with mRS (modified Rankin Scale) to give a mark. In accordance with the mRS score, the prognosis results can be classified as excellent (0-2), medium (3), bad (4-6). NIGSS can be used in the preoperative follow-up. Make DSA or CTA examination 3 months, 6 months, 12 months later after the operation as the imaging follow-up. The restenosis standard is $250 \%$ of vascular stenosis of $3 \mathrm{~mm}$ in the stent and the both ends of the 
stent. The measurement method takes the WASID standard.

\section{Statistical analysis}

SPSS 18.0 was used for statistical analysis, all data are expressed with means \pm SD. One-way ANOVA was adopted to analyze data, the comparison of two groups takes Fisher exact test. $\mathrm{p}<$ 0.05 represents that the difference is significant; $\mathrm{p}<$ 0.01 represents that the difference is greatly significant.

\section{Results}

The patients with acute basilar artery occlusion were treated thrombolytic therapy combined with interventional therapy got a better survival condition than individual therapy

In order to investigate the survival of the patients with acute basilar artery occlusion in the experimental group (thrombolytic therapy group, thrombolytic therapy combined with interventional therapy group) and the control group, we adopted different strategies to perform the operations and analyzed the curative effects of all groups in 24 hours, 14 days, 90 days after the operation. Our result showed that survival of the patients treated with thrombolytic therapy were better than in the control group $(\mathrm{p}<0.05)$. Moreover, we further found that the survival of the patients in the combined group were significantly superior to the control group $(p<0.01)$. Furthermore, we next compare the survival difference of the combined group and thrombolytic therapy group. Our data indicated that the patients in the combined group had a better survival than that in the group of thrombolytic therapy $(\mathrm{p}<0.05)$ (Table 1$)$. In addition, the color Doppler ultrasound images before and after treatment showed that in the combined group had a better survival than that in the group of thrombolytic therapy and control group (Figure 1). Altogether, these data implied that the combined treatment is more effective than thrombolytic therapy alone to improve the survival of the patients with acute basilar artery occlusion.

Table 1 The comparison of survival conditions in groups (n, \%).

\begin{tabular}{|c|c|c|c|c|}
\hline Group & Cases & $24 \mathrm{~h}$ & $14 \mathrm{~d}$ & $90 \mathrm{~d}$ \\
\hline Control group & 25 & $20(80.0 \%)$ & $16(64.0 \%)$ & $10(40.0 \%)$ \\
\hline $\begin{array}{l}\text { Thrombolytic therapy } \\
\text { group }\end{array}$ & 24 & $21(87.5 \%)^{a}$ & $17(70.8 \%)^{a}$ & $14(58.3 \%)^{a}$ \\
\hline $\begin{array}{l}\text { Combination } \\
\text { thrombolytic therapy } \\
\text { with interventional } \\
\text { therapy group }\end{array}$ & 26 & $24(92.3 \%)^{\mathrm{ab}}$ & $20(76.9 \%)^{a b}$ & $16(66.7 \%)^{a b}$ \\
\hline
\end{tabular}

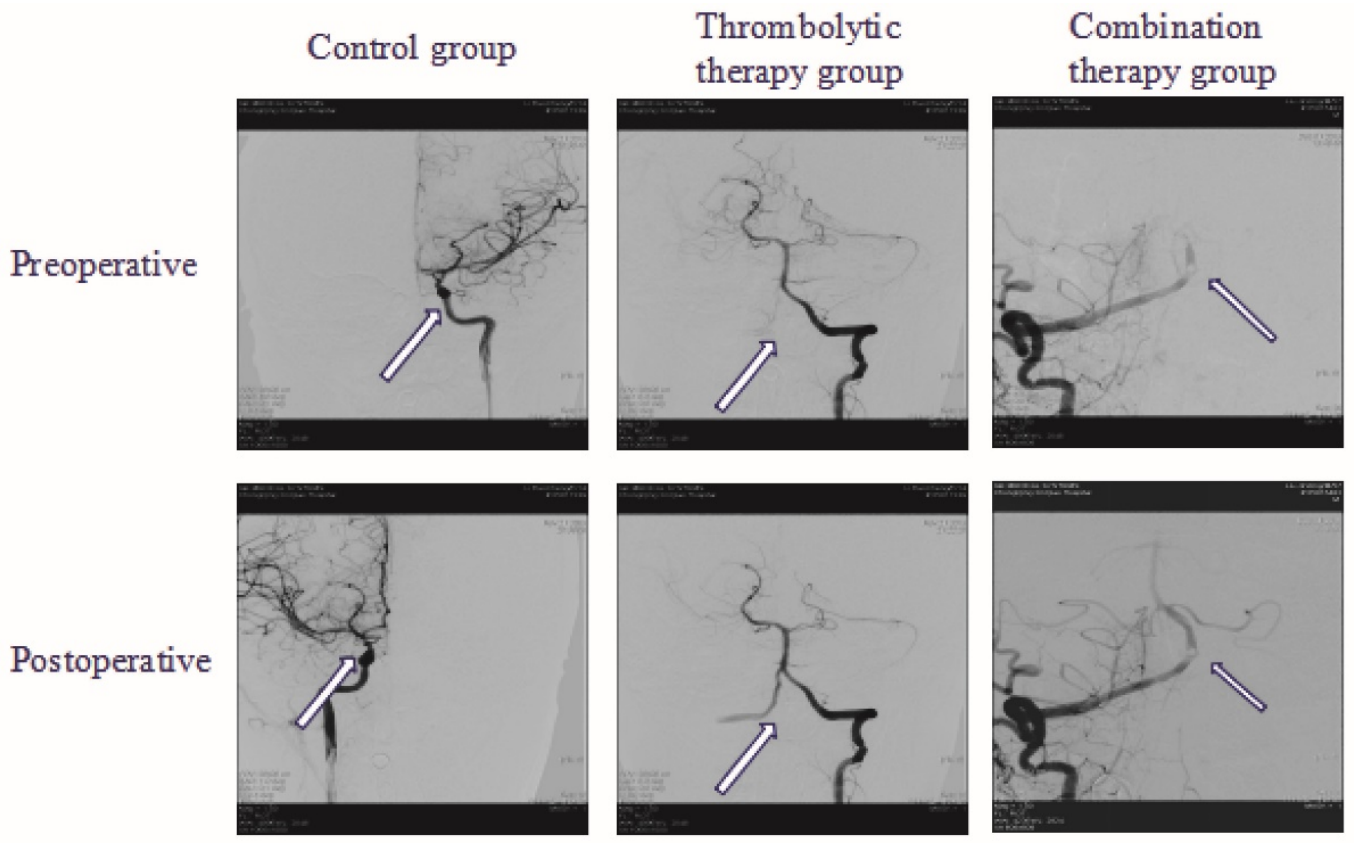

Figure 1 Color Doppler Ultrasound images from preoperative and postoperative showed that in the combination therapy group had a better survival than that in the group of thrombolytic therapy group and control group. 


\section{The patients with acute basilar artery occlusion were treated thrombolytic therapy combined with interventional therapy had a lower NIHSS score}

In order to explore the effects of combination thrombolytic therapy with interventional therapy on patients with acute basilar artery occlusion, we adopted different strategies to perform the operations, and then analyzed the NIHSS score of all groups in 24 hours, 14 days, 90 days after the operation. The result showed that the NIHSS scores of patients in each experimental group were obviously decreased compared to the control group $(p<0.05)$, which proved that different therapy had a positive impact on the patients. Besides, we further analyzed the difference of the NIHSS score of patients in the combined group and thrombolytic therapy group. Our results showed that the patients in the combined treatment group had a lower NIHSS score than that thrombolytic therapy group $(\mathrm{p}<0.05)$. These results suggested that combined treatment is more favorable than thrombolytic therapy alone to improve the survival status of patients (Table 2).

Table 2 The comparison of NIHSS scores after the treatment in groups (\%).

\begin{tabular}{|c|c|c|c|c|c|}
\hline Group & Cases & $\begin{array}{l}\text { Before } \\
\text { treatment }\end{array}$ & $24 \mathrm{~h}$ & $14 \mathrm{~d}$ & $90 \mathrm{~d}$ \\
\hline Control group & 25 & $14.09 \pm 3.25$ & $13.85 \pm 3.03$ & $11.24 \pm 4.32$ & $5.49 \pm 2.11$ \\
\hline $\begin{array}{l}\text { Thrombolytic therapy } \\
\text { group }\end{array}$ & 24 & $14.53 \pm 2.96$ & $12.14 \pm 2.85$ & $8.38 \pm 4.02^{\mathrm{a}}$ & $2.45 \pm 1.03^{a}$ \\
\hline $\begin{array}{l}\text { Combination } \\
\text { thrombolytic therapy } \\
\text { with interventional } \\
\text { therapy group }\end{array}$ & 26 & $14.94 \pm 3.46$ & $10.84 \pm 2.42^{b c}$ & $6.34 \pm 3.24^{b c}$ & $1.57 \pm 0.74^{\mathrm{bc}}$ \\
\hline
\end{tabular}

Note: a represents that $\mathrm{p}<0.05$ compare to control group, ${ }^{\mathrm{b}}$ represents that $\mathrm{p}<0.01$ compare to the control group, $c$ represents that $\mathrm{p}<0.05$ compare with the thrombolytic therapy group.

\section{The patients with acute basilar artery occlusion were treated thrombolytic therapy combined with interventional therapy had a higher BI score and lower $\mathrm{mRS}$ score}

In order to explore the effect of combination thrombolytic therapy with interventional therapy on patients living quality with acute basilar artery occlusion, we adopted different methods to perform the operations, and then analyzed the BI scores and mRS scores of the experimental groups in 24 hours, 14 days, 90 days after the operation. Our results suggested that the BI scores of patients in the experimental groups were significantly higher than the control group $(p<0.05, p<0.05)$, implied that the of thrombolytic therapy alone and combined treatment had a certain curative effect on the patients. In addition, our data also indicated that BI scores of the patients in the combined treatment group was higher than thrombolytic therapy group $(\mathrm{p}<0.05)$. Furthermore, we next analyzed the mRS scores of the patients in different treatment group after 90 days. The results displayed that mRS scores of the patients in combination group were evidently lower than the control group and thrombolytic therapy group $(\mathrm{p}<0.01)$ (Table 3).

Table 3 Comparison of $\mathrm{BI}$ and $\mathrm{mRS}$ scores after the treatment (\%).

\begin{tabular}{|c|c|c|c|c|}
\hline \multirow[t]{2}{*}{ Group } & \multirow[t]{2}{*}{ Cases } & \multicolumn{3}{|c|}{ BI } \\
\hline & & $14 \mathrm{~d}$ & $90 \mathrm{~d}$ & $90 \mathrm{~d}$ mRS \\
\hline Control group & 25 & $48.34 \pm 24.26$ & $57.73 \pm 30.17$ & $3.58 \pm 2.18$ \\
\hline Thrombolytic therapy group & 24 & $65.84 \pm 22.19^{a}$ & $83.74 \pm 35.21^{\mathrm{a}}$ & $1.56 \pm 0.23^{\mathrm{a}}$ \\
\hline $\begin{array}{l}\text { Combination thrombolytic } \\
\text { therapy with interventional } \\
\text { therapy group }\end{array}$ & 26 & $78.18 \pm 24.83^{\mathrm{bc}}$ & $99.93 \pm 38.47 \mathrm{bc}$ & $0.95 \pm 0.14^{\text {bc }}$ \\
\hline
\end{tabular}

Treated by combination thrombolytic therapy with interventional therapy, coagulation related factors remarkably improved

In order to explore the effects of combination thrombolytic therapy with interventional therapy on the coagulation related factors in the patients with acute basilar artery occlusion, the coagulation related factors were detected in patients before and after treatment. Our data showed that there was rarely significant difference for coagulation related factors before treatment in each experimental group. However, our results showed that compared with the control group, the level of fibrinogen, D-dimer, a2 anti-fibrinolytic enzyme and plasminogen in the patients were treated thrombolytic therapy combined with interventional therapy group were significantly decreased, while the fibrin degradation products were obviously increased $(\mathrm{p}<0.05, \mathrm{p}<0.05, \mathrm{p}<0.05, \mathrm{p}<0.05$, $\mathrm{p}<0.05)$ (Table 4). Moreover, our results also showed that compared with the control group, the level of coagulation factor XIII and platelet had no significantly changes in the patients were treated thrombolytic therapy combined with interventional therapy group. And our data also showed that there was no significant difference in coagulation related factors between the combined treatment group with the thrombolytic therapy group. These data suggested that the blood clotting ability was significantly lower in patients treated with thrombolytic therapy, which is helpful to the dissolution of the thrombolytic. However, there was no effect on the improvement of 
the coagulation conditions by the operation of the interventional therapy.

\section{The prognosis of the patients was obviously affected by the coma, bilateral Babinski(+), revascularization and shaping method}

For further discuss the factors that may affect the treatment and prognosis of the patients with acute basilar artery occlusion, we adopted a introspective analysis on the basic information of the patients treated by thrombolytic therapy and the combined therapy. Our results revealed that the prognosis of patients was scarcely affected by sex, age, onset to thrombolysis time $(\mathrm{p}>0.05, \mathrm{p}>0.05, \mathrm{p}>0.05)$. Moreover, our data also indicated that the prognosis of the patients with dizziness, visual rotation, ocular ataxia had no difference with the patients without these symptoms $(p>0.05, p>0.05, p>0.05)$. However, the prognosis of the patients with coma, bilateral Babinski(+) were obviously worse than that of the patients without these symptoms $(\mathrm{p}<0.05, \mathrm{p}<$ 0.05 ). Besides, the prognosis of patients with good revascularization and stent angioplasty were significantly superior to the patients with poor revascularization and non-stent angioplasty $(p<0.05$, $\mathrm{p}<0.05)$ (Table 5).

\section{Discussion}

Acute basilar artery occlusion is characterized by rapid onset and the mortality rate is high. Even if the patients survived, they will be acquired different degree of disability [17]. Therefore, effectively diagnosis and reasonable treatment strategies have great a significance to improve the prognosis of patients with acute basilar artery occlusion [18]. Nowadays, it's able to know whether the patient is suffered from basilar artery occlusion, which in accordance with the general clinic features and imaging examination $[19,20]$, and the primary treatment strategy is thrombolytic therapy. Kobayashi et al. reported that the local drug concentration can be effectively enhanced by puncturing arterial thrombolysis through femoral artery, eventually obviously improve the clinical treatment efficiency $[21,22]$. In the current study, we adopted the strategy of thrombolytic therapy combined with interventional therapy to reduce the proportion of the early adverse prognosis. Our data illustrated that the patients with acute basilar artery occlusion could have a good prognosis, when they received thrombolytic therapy actively. Besides, the increasing improvement of the imaging technology makes the examination of CT and/or MRI more effectively diagnose the basilar artery occlusion and precisely locate the lesion [14, 23], just like that of diagnosing occupying lesion, such as tumor, in brain [24, 25].

In the current study, our results showed arterial thrombolysis combined with interventional therapy has more efficient effect on treating the patients with basilar artery occlusion in the short stage. The survival rate of the patients is $92.3 \%$ and $66.7 \%$ in 24 hours and 90 days, respectively. There were 7 cases that died of pulmonary infection during long-term follow-up. Therefore, it is important that sputum drainage training and nursing should be strengthened for the patients with basilar artery occlusion, avoiding the occurrence of aspiration and pneumonia, especially for the patients who suffer from long-term bed rest and disturbance of unconsciousness [9]. Our data indicated that the patients treated with combined treatment had higher BI and lower NIHSS scores and mRS scores than treated with thrombolytic therapy alone, which proved that the survival conditions of the patients have been greatly improved.

Table 4 The changes of blood coagulation indexes before and after treatment.

\begin{tabular}{|c|c|c|c|c|c|}
\hline Grouping & & Control group & $\begin{array}{l}\text { Thrombolytic therapy } \\
\text { group }\end{array}$ & $\begin{array}{l}\text { Combination } \\
\text { therapy group }\end{array}$ & $P$ value \\
\hline \multirow[t]{2}{*}{ Fibrous protein $(\mathrm{g} / \mathrm{L})$} & Before treatment & $3.59 \pm 0.98$ & $3.65 \pm 0.92$ & $3.57 \pm 0.88$ & 0.894 \\
\hline & After treatment $4 \mathrm{hr}$ & $3.42 \pm 0.85$ & $2.38 \pm 0.61$ & $2.30 \pm 0.68$ & 0.038 \\
\hline \multirow[t]{2}{*}{ Fibrin degradation products $(\mu \mathrm{g} / \mathrm{ml})$} & Before treatment & $7.58 \pm 7.65$ & $7.62 \pm 7.70$ & $7.54 \pm 7.67$ & 0.974 \\
\hline & After treatment $4 \mathrm{hr}$ & $10.43 \pm 9.89$ & 42. $75 \pm 51.04$ & $43.27 \pm 49.35$ & 0.022 \\
\hline \multirow[t]{2}{*}{ D-dimer (mg /L) } & Before treatment & $0.91 \pm 1.29$ & $0.94 \pm 1.23$ & $0.97 \pm 1.31$ & 0.940 \\
\hline & After treatment $4 \mathrm{hr}$ & $1.12 \pm 1.37$ & $2.32 \pm 2.65$ & $2.38 \pm 2.71$ & 0.031 \\
\hline \multirow[t]{2}{*}{ Coagulation factor XIII (\%) } & Before treatment & $108.14 \pm 23.31$ & $107.13 \pm 22.97$ & $110.17 \pm 24.72$ & 0.842 \\
\hline & After treatment $4 \mathrm{hr}$ & $101.63 \pm 21.87$ & $98.34 \pm 19.63$ & $197.64 \pm 18.99$ & 0.231 \\
\hline \multirow[t]{2}{*}{ a2 anti-fibrinolytic enzyme (\%) } & Before treatment & $105.27 \pm 15.74$ & $107.95 \pm 17.65$ & $109.43 \pm 16.19$ & 0.645 \\
\hline & After treatment $4 \mathrm{hr}$ & $95.67 \pm 12.65$ & $37.84 \pm 11.36$ & $35.95 \pm 10.29$ & 0.029 \\
\hline \multirow[t]{2}{*}{ Plasminogen (\%) } & Before treatment & $107.37 \pm 15.74$ & $109.28 \pm 16.39$ & $105.63 \pm 15.03$ & 0.741 \\
\hline & After treatment $4 \mathrm{hr}$ & $100.24 \pm 13.45$ & $66.38 \pm 9.27$ & $63.21 \pm 8.75$ & 0.022 \\
\hline \multirow[t]{2}{*}{ Platelet $\left(\times 10^{3} / \mathrm{ml}\right)$} & Before treatment & $278.36 \pm 70.32$ & $270.21 \pm 73.77$ & $283.42 \pm 75.04$ & 0.382 \\
\hline & After treatment $4 \mathrm{hr}$ & $268.41 \pm 60.29$ & $265.38 \pm 57.29$ & $271.04 \pm 64.04$ & 0.274 \\
\hline
\end{tabular}


Table 5 Factors that may affect the prognosis of treating basilar artery occlusion.

\begin{tabular}{|c|c|c|c|c|}
\hline $\begin{array}{l}\text { Outcome } \\
\text { measures }\end{array}$ & Cases (n) & $\begin{array}{l}\text { Good } \\
\text { prognosis }\end{array}$ & $\begin{array}{l}\text { Poor } \\
\text { prognosis }\end{array}$ & $P$ value \\
\hline \multicolumn{5}{|l|}{ Gender } \\
\hline Male & 35 & 21 & 14 & 0.837 \\
\hline Female & 15 & 9 & 6 & \\
\hline \multicolumn{5}{|l|}{ Age } \\
\hline$<60$ years & 36 & 22 & 14 & 0.329 \\
\hline$\geq 60$ years & 14 & 10 & 4 & \\
\hline \multicolumn{5}{|c|}{$\begin{array}{l}\text { Onset to } \\
\text { thrombolysis } \\
\text { time }\end{array}$} \\
\hline$<12 \mathrm{~h}$ & 40 & 25 & 15 & 0.693 \\
\hline$\geq 12 \mathrm{~h}$ & 10 & 6 & 4 & \\
\hline \multicolumn{5}{|l|}{ Dizziness } \\
\hline No & 14 & 8 & 6 & 0.754 \\
\hline Yes & 36 & 22 & 14 & \\
\hline \multicolumn{5}{|l|}{ Coma } \\
\hline No & 37 & 27 & 10 & 0.002 \\
\hline Yes & 13 & 3 & 10 & \\
\hline \multicolumn{5}{|c|}{ Ocular tremor } \\
\hline No & 37 & 20 & 17 & 0.874 \\
\hline Yes & 13 & 8 & 5 & \\
\hline \multicolumn{5}{|c|}{$\begin{array}{l}\text { Bilateral Babinski } \\
(+)\end{array}$} \\
\hline No & 21 & 18 & 3 & 0.001 \\
\hline Yes & 29 & 11 & 18 & \\
\hline \multicolumn{5}{|l|}{$\begin{array}{l}\text { Embolism } \\
\text { position }\end{array}$} \\
\hline Near-end & 33 & 23 & 10 & 0.241 \\
\hline Far-end & 17 & 10 & 7 & \\
\hline \multicolumn{5}{|c|}{ Revascularization } \\
\hline Good & 33 & 23 & 10 & 0.002 \\
\hline Poor & 17 & 4 & 13 & \\
\hline \multicolumn{5}{|c|}{ Angiopoiesis } \\
\hline No & 35 & 22 & 13 & 0.438 \\
\hline Yes & 15 & 8 & 7 & \\
\hline \multicolumn{5}{|c|}{ Shaping methods } \\
\hline Balloon & 8 & 3 & 5 & 0.001 \\
\hline Stent & 18 & 16 & 2 & \\
\hline
\end{tabular}

Furthermore, the introspective analysis showed that the occurrence stage of thrombolysis was no closely correlation with the prognosis of the patients with basilar artery occlusion. Powers et al. have reported that the time stage of thrombolysis treatment was long, which can be extended to 12 hours after occurrence, or even longer [26]. The effects of the treatment of posterior circulation artery thrombolytic therapy are vary greatly from individual to individual $[6,9,27,28]$. Furthermore, our results also showed that the patients with bilateral Babinski (+) and coma symptom have close correlation with the poor prognosis. The other researchers have also reported that poor prognosis of patients who were hospitalized with coma and bilateral paralysis. It may be caused by simultaneous involvement of bilateral conduction pathways. Once occurs a large ischemia in the brain stem, the brain will suffer serious damage, which is very important for the neurologic function evaluation $[29,30]$.
Now most investigators consider that vascular reperfusion is a direct strategy for basilar artery occlusion treatment, which can effectively reduce the mortality of patients. In addition, our data also implied that the blood clotting ability was significantly lowered in patients treated with thrombolytic therapy, which is useful to the dissolution of the thrombolytic. However, there was rarely influenced on the improvement of the coagulation conditions by treating the patients with interventional therapy. These data suggested that the strategy of combination therapy can effectively and safely be used in the clinical trial. Our data further indicated that recanalization rate and prognosis of stent angioplasty were better than balloon angioplasty. Therefore, treatment basilar artery occlusion with arterial thrombolysis should be timely taken stent angioplasty to improve the prognosis of basilar artery occlusion.

In summary, thrombolytic therapy should be used soon to treatment the patients with acute basilar artery occlusion. Much attention should be paid on symptomatic hemorrhage, venerable age, baseline blood pressure, and neurologic impairment score, and so on, which are closely associated with early prognosis. Moreover, combination arterial thrombolysis therapy with interventional therapy can effectively improve the prognosis of patients with basilar artery occlusion. We considered that the advantage of arterial thrombolytic therapy had a higher recanalization rate, but possess the shortcoming which had more time consuming on preoperative preparation and radiography. Therefore, it makes the advantages of arterial thrombolysis could stand out, if the diagnosis and treatment process for arterial thrombolysis can be regulated, the quality of instruments for arterial thrombolysis is improved, and enhanced the operation technique of interventional doctor.

\section{Competing Interests}

The authors have declared that no competing interest exists.

\section{References}

1 Strbian D, Sairanen T, Silvennoinen H, Salonen O, Kaste M, Lindsberg PJ. Thrombolysis of BAO: impact of baseline ischemia and time. Ann Neurol. 2013;73:688-94.

2 Meretoja A, Strbian D, Putaala J, Kaste M, Tatlisumak T. Hemiplegia and thrombolysis. Eur J Neurol. 2012;19:1235-8.

3 Taneja SR, Hanna I, Holdgate A, Wenderoth J, Cordato DJ. BAO in a 14-year old female successfully treated with acute intravascular intervention: case report and review of the literature. J Paediatr Child Health. 2011;47:408-14.

4 Mattle HP, Arnold M, Lindsberg PJ, Schonewille WJ, Schroth G. BAO. Lancet Neurol 2011;10:1002-14.

5 Calvet D, Bracard S, Mas JL. Treatment of arterial and venous brain ischemia. Experts' recommendations: stroke management in the intensive care unit. Rev Neurol (Paris). 2012;168:512-21.

6 Wang L, Shi W, Su Z, Liu X, Su H, Liu J, Liu Z, Lawton MT. Endovascular treatment of severe acute BAO. J Clin Neurosci. 2015;22:195-8. 
7 Lindsberg PJ, Mattle HP. Therapy of BAO: a systematic analysis comparing intra-arterial and intravenous thrombolysis. Stroke. 2006;37:922-8.

8 Amiri H, Hacke W, Bosel J. Thrombolytic treatment of acute stroke. Internist (Berl). 2011;52:1310, 1312-16.

9 Sairanen T, Strbian D, Ruuskanen R, Silvennoinen H, Salonen O, Lindsberg PJ. Symptomatic intracranial haemorrhage after thrombolysis with adjuvant anticoagulation in BAO. Eur J Neurol. 2015;22:493-9.

10 Hassan A, ul Haq T, Khimani F, Ali S, Dhakam S, Syed NA. Acute vertebrobasilar artery thrombosis: long-term benefit of vertebral artery stenting. Singapore Med J. 2007;48:e277-80.

11 Gonzalez A, Mayol A, Martinez E, Gonzalez-Marcos JR, Gil-Peralta A. Mechanical thrombectomy with snare in patients with acute ischemic stroke. Neuroradiology. 2007;49:365-372.

12 Grond M, Rudolf J, Schmulling S, Stenzel C, Neveling M, Heiss WD. Early intravenous thrombolysis with recombinant tissue-type plasminogen activator in vertebrobasilar ischemic stroke. Arch Neurol. 1998;55:466-9.

13 Kamiya Y, Ichikawa H, Mizuma K, Itaya K, Shimizu Y, Kawamura M. Case of acute ischemic stroke due to cardiac myxoma treated by intravenous thrombolysis and endovascular therapy. Rinsho Shinkeigaku. 2014;54:502-6.

14 Schmitt R, Christopoulos G, Salveter E, Ziegler V, Brunner H, Wedell E, Griewing B. Diagnostic angiography using multi-slice spiral CT in acute obstruction of the basilar artery. Rontgenpraxis. 2004;55:184-91.

15 Bergui M, Stura G, Daniele D, Cerrato P, Berardino M, Bradac GB. Mechanical thrombolysis in ischemic stroke attributable to $\mathrm{BAO}$ as first-line treatment. Stroke. 2006;37:145-50.

16 Bodey C, Goddard T, Patankar T, Childs AM, Ferrie C, McCullagh H, Pysden $\mathrm{K}$. Experience of mechanical thrombectomy for paediatric arterial ischaemic stroke. Eur J Paediatr Neurol. 2014;18:730-5.

17 Endo K, Koga M, Sakai N, Yamagami H, Furui E, Matsumoto Y, Shiokawa Y, Yoshimura S, Okada Y, Nakagawara J, Hyogo T, Hasegawa Y, Nagashima H, Fujinaka T, Hyodo A, Terada T, Toyoda K. Stroke outcomes of Japanese patients with major cerebral artery occlusion in the post-alteplase, pre-MERCI era. J Stroke Cerebrovasc Dis. 2013;22:805-10.

18 Mourand I, Machi P, Milhaud D, Picot MC, Lobotesis K, Arquizan C, Costalat V, Heroum C, Sablot D, Bouly S, Lalu T, Bonafe A. Mechanical thrombectomy with the Solitaire device in acute BAO. J Neurointerv Surg. 2014;6:200-4.

19 Yeo LL, Paliwal PR, Wakerley B, Khoo CM, Teoh HL, Ahmad A, Ting EY, Seet RC, Ong V, Chan BP, Yohanna K, Gopinathan A, Rathakrishnan R, Sharma VK. External validation of the Boston Acute Stroke Imaging Scale and M1-BASIS in thrombolyzed patients. Stroke. 2014;45:2942-7.

20 Zhang J, Guan I, Oi X, Ding H, Yuan H, Xie Z, Chen C, Li X, Zhang C, Huang Y. Dimethyloxaloylglycine Promotes the Angiogenic Activity of Mesenchymal Stem Cells Derived from iPSCs via Activation of the PI3K/Akt Pathway for Bone Regeneration. Int J Biol Sci. 2016; 12:639-52.

21 Kobayashi S, Miyamoto M, Shinada S, Ishi Y, Shimoda Y, Yamazaki K, Ushikoshi S, Ooka T, Matsui Y, Houkin K. Successful acute endovascular therapy of cerebral embolism for a patient with ventricular assist device: a case report. No Shinkei Geka. 2014;42:1057-62.

22 Renard D, Landragin N, Robinson A, Brunel H, Bonafe A, Heroum C, Milhaud C. MRI-based score for acute basilar artery thrombosis. Cerebrovasc Dis. 2008;25:511-6.

23 Liu H, Wei X, Kong L, Liu X, Cheng L, Yan S, Zhang X, Chen L. NOD2 is involved in the inflammatory response after cerebral ischemia-reperfusion injury and triggers NADPH oxidase 2-derived reactive oxygen species. Int J Biol Sci. 2015;11:525-35.

24 Jing Cai, Yilin Liu, Fangfang Yin. Extracting Breathing Signal Using Fourier Transform from Cine Magnetic Resonance Imaging. Cancer Translational Medicine. 2015;1: 16-20.

25 Jinrong Qu, Xiang Li, Lei Qin, Lifeng Wang, Junpeng Luo, Jianwei Zhang, Hongkai Zhang, Jing Li, Fei Sun, Shouning Zhang, Yanle Li, Cuicui Liu, Hailiang Li. Comparison of Intra-voxel Incoherent Motion Diffusion Magnetic Resonance Imaging and Apparent Diffusion Coefficient in the Evaluation of Focal Malignant Liver Masses. Cancer Translational Medicine. 2015;1: 11-15.

26 Powers WJ. Endovascular (intraarterial) treatment of acute ischemic stroke efficacy not supported by clinical trials. South Med J. 2014;107:101-6.

27 Savastano L, Gemmete JJ, Pandey AS, Roark C, Chaudhary N. Acute ischemic stroke in a child due to basilar artery occlusion treated successfully with a stent retriever. J Neurointerv Surg. 2016;8:e33.

28 Yoshimura S, Sakai N, Okada Y, Kitagawa K, Kimura K, Tanahashi N, Hyogo T, Yamagami H, Egashira Y. Efficacy of endovascular treatment for acute cerebral large-vessel occlusion: analysis of nationwide prospective registry. J Stroke Cerebrovasc Dis. 2014;23:1183-90.

29 Starr PA, Barbaro NM, Raskin NH, Ostrem JL. Chronic stimulation of the posterior hypothalamic region for cluster headache: technique and 1-year results in four patients. J Neurosurg. 2007;106:999-1005.

30 Yang FC, Lin CC, Hsueh CJ, Lee JT, Hsu CH, Lee KW, Peng GS. Local intra-arterial thrombolysis with urokinase for acute ischemic stroke before and after the approval of intravenous tissue plasminogen activator treatment in Taiwan. Ann Vasc Surg. 2010;24:1117-24. 